\title{
Переваримость кормов и обмен веществ молодняка крупного рогатого скота при введении в рацион минеральных комплексов
}

\author{
А.М. Макаева ${ }^{1}$, Е.А. Сизова ${ }^{1,2}$, К.Н. Атландерова ${ }^{1}$ \\ ${ }^{I}$ Федеральный научный центр биологических систем и агротехнологий Российской академии наук (2. Оренбург) \\ ${ }^{2}$ Оренбургский государственный университет (2. Оренбург)
}

\begin{abstract}
Аннотация. Неподдельный интерес у научного сообщества вызывает вопрос изучения результатов применения различных форм минеральных кормовых добавок с целью повышения продуктивности сельскохозяйственных животных. В статье приведены результаты исследований обмена веществ и переваримости корма у молодняка крупного рогатого скота при введении в рацион высокодисперсных частиц (ВДЧ) $\mathrm{SiO}_{2}$ (I группа) и $\mathrm{FeCo}$ (II группа) с гидродинамическим радиусом $109,6 \pm 16,6$ и $265 \pm 25$ нм соответственно.

В эксперименте показано, что наиболее высокими показателями переваримости большинства питательных веществ обладали бычки, получавшие ВДЧ $\mathrm{SiO}_{2}$.

Поступление же энергии в организм было практически одинаковым. Переваримой энергии бычки потребляли больше в I и II группе на 2,9 \% $(\mathrm{P} \leq 0,01)$ и на $3,1 \%$ ( $\mathrm{P} \leq 0,01)$ относительно контроля. Обменная энергия в I и II группах превосходила контрольную группу на 12 и 2 МДж.

Введение ВДЧ сопровождается увеличением переваривания азота на $10,3 \%(\mathrm{P} \leq 0,05)$ в I группе и на $13,1 \%(\mathrm{P} \leq 0,01)$ - во II группе по сравнению с контрольной. Главенствующую позицию занимала II группа, у бычков которой коэффициент использования азота от принятого был выше, чем в контрольной и в I опытной группах, а коэффициент использования азота от переваренного - на $76,5 \%(\mathrm{P} \leq 0,01)$ и $15,4 \%(\mathrm{P} \leq 0,01)$ соответственно.

Таким образом, скармливание животным ВДЧ микроэлементов сопровождается повышением коэффициентов переваримости питательных веществ рационов с выраженным эффектом для ВДЧ $\mathrm{SiO}_{2}$

Ключевые слова: крупный рогатый скот, бычки, красная степная порода, кормление, переваримость питательных веществ, высокодисперсные частицы, обмен энергии, обмен азота.
\end{abstract}

UDC 636.084.1:636.088.31

Digestibility of feed and metabolism of young cattle after mineral complexes introduced into the diet

\author{
Aina M Makaeva ${ }^{1}$, Elena A Sizova ${ }^{1,2}$, Kseniya $N$ Atlanderova ${ }^{1}$ \\ ${ }^{1}$ Federal Research Centre of Biological Systems and Agrotechnologies of the Russian Academy of Sciences (Orenburg, Russia) \\ ${ }^{2}$ Orenburg State University (Orenburg, Russia)
}

Summary. The genuine interest of scientific community is the question of studying the results of applying various forms of mineral feed additives in order to increase the productivity of farm animals. The article presents the results of studies of metabolism and digestibility of feed of young cattle with the introduction of highly dispersed particles (HDP) $\mathrm{SiO}_{2}$ (group I) and $\mathrm{FeCo}$ (group II) with hydrodynamic radius of $109.6 \pm 16.6$ and $265 \pm 25 \mathrm{~nm}$ respectively.

It was shown in the experiment that bulls that received $\mathrm{SiO}_{2} \mathrm{HDP}$ had the highest digestibility indices for the majority of nutrients.

The intake of energy in the body was almost the same. The bulls of group I and II consumed more digestible energy by $2.9 \%(\mathrm{P} \leq 0.01)$ and $3.1 \%(\mathrm{P} \leq 0.01)$ relative to the control. Metabolic energy in groups I and II exceeded the control group by 12 and $2 \mathrm{MJ}$.

The introduction of HDP is accompanied by an increase in nitrogen digestion by $10.3 \%(\mathrm{P} \leq 0.05)$ in group I and by $13.1 \%(\mathrm{P} \leq 0.01)$ in group II compared to the control. The dominant position was occupied by 
group II, nitrogen utilization rate of bulls from that group was higher than in the control and in group I, and the nitrogen utilization rate from the digested one was higher by $76.5 \%(\mathrm{P} \leq 0.01)$ and $15,4 \%(\mathrm{P} \leq 0.01)$, respectively.

Thus, feeding animals with HDP of microelements is accompanied by an increase in the digestibility ratios of nutrients in diets with a pronounced effect for $\mathrm{SiO}_{2} \mathrm{HDPs}$.

Key words: cattle, bulls, Red Steppe Breed, feeding, digestibility of nutrients, highly dispersed particles, energy exchange, nitrogen exchange.

\section{Введение.}

Жвачные имеют преимущества в использовании кормовых субстратов, которые реализуются благодаря симбиотической ассоциации с микрофлорой рубца и кишечника. Рубец животных содержит множество консалидированных групп анаэробных микроорганизмов, которые осуществляют разнообразные метаболические процессы (Bergmann GT, 2017; Фисинин В.И. и др., 2016; Rosenberg E et al., 2013). Понимание закономерностей функционирования микробиома рубца и его изменчивости в условиях различного питания, возможно, является ключом к оценке и повышению эффективности переваривания, и в итоге - к повышению продуктивности крупного рогатого скота.

Нарушение качественного и количественного составов микробиома приводит к снижению интенсивности пищеварения и продуктивности животных. На микробиом рубца влияют различные факторы, в том числе питание (Zeineldin M et al., 2018; Zhu W et al., 2013; Henderson G et al., 2015; Walsh K et al., 2009; Torok VA et al., 2014). Следовательно, фактор кормления является определяющим при оценке состава и функциональной активности рубцового микробного сообщества, а познание его изменения в условиях различного питания, возможно, является ключом к совершенствованию сельскохозяйственного производства.

В последнее время актуальность приобретают исследования применения различных форм микроэлементов в кормлении животных (Gorlov IF et al., 2015; Сизова Е.А., 2017a). В частности, микроэлементы в высокодисперсной форме являются перспективными компонентами рациона животных (Prasad R et al., 2017; Miroshnikova E et al., 2015; Сизова Е.А. и др., 2018; Яушева Е.В. и др., 2013), в том числе в качестве источников микроэлементов (Wang C et al., 2011; Богословская О.А. и др., 2007), иммуномодууляторов (Fondevila M et al., 2009) и стимуляторов роста (Wang MQ et al., 2012, Wang MQ et al., 2014) и др.

Отмечается, что недостаток в рационах жвачных микроэлементов вызывает нарушения жизнедеятельности организма и приводит к снижению продуктивности сельскохозяйственных животных (Венедиктова А.М., 1990; Кальницкий Б.Д., 1990).

Таким образом, актуальным является изучение использования основных питательных веществ у молодняка крупного рогатого скота при введении в рацион ВДЧ микроэлементов.

\section{Цель исследования.}

Изучение переваримости питательных веществ, эффективности использования азота и энергии подопытными животными при введении в рацион ВДЧ микроэлементов.

\section{Материалы и методы исследования.}

Объект исследования. Бычки красной степной породы в возрасте 13 месяцев.

Обслуживание животных и экспериментальные исследования были выполнены в соответствии с инструкциями и рекомендациями Russian Regulations, 1987 (Order No. 755 on 12.08.1977 the USSR Ministry of Health) and «The Guide for Care and Use of Laboratory Animals (National Academy Press Washington. D.C. 1996). При выполнении исследований были предприняты усилия, чтобы свести к минимуму страдания животных и уменьшения количества образцов.

Схема эксперимента. Исследования проводились на базе Центра коллективного пользования Федерального научного центра биологических систем и агротехнологий Российской академии наук и Покровского сельскохозяйственного колледжа-филиала Оренбургского государственного аграрного университета. В качестве источников микроэлементов были использованы препараты 
ВДЧ $\mathrm{SiO}_{2}\left(\mathrm{SiO}_{2}: 99,8 \%, \mathrm{Cl}_{2}:<0,2 \% ; \mathrm{S}_{\mathrm{yд}}=55,4 \mathrm{~m}^{2} / \Gamma ; \mathrm{Z}\right.$-потенциалом $\left.-31 \pm 0,5 \mathrm{мB}\right)$ и ВДЧ сплава $\mathrm{FeCo}$ (Fe: $70 \%$, Co: $30 \%$; $\mathrm{S}_{\mathrm{yд}}=15,4 \mathrm{~m}^{2} / \Gamma$; Z-потенциалом $15 \pm 0,2 \mathrm{mB}$ ) с гидродинамическим радиусом в водном лиозоле $109,6 \pm 16,6$ нм и $265 \pm 25$ нм. Подготовку препаратов ВДЧ проводили в изотоническом растворе на ультразвуковом диспергаторе УЗДН-2Т («НПП Академприбор», Россия) (35 кГц, $300 / 450$ Вт, 10 мкА) в течение 30 мин.

Для проведения физиологического опыта были подобраны 9 бычков красной степной породы методом пар-аналогов по живой массе, общему состоянию, породе и возрасту. В опыт включались бычки возраста 13 месяцев. Животные были случайным образом разделены на группы: на контрольную (K) и две опытные - I $\left(\mathrm{SiO}_{2}\right)$, II ( $\left.\mathrm{FeCo}\right)$.

В течение подготовительного периода (10 суток) бычки были переведены на привязное содержание, индивидуальное кормление.

Исследования на животных проводились в соответствии с «Правилами проведения работ с использованием лабораторных животных» (прил. к приказу Министерства здравоохранения СССР, от 12.08.1977 №755).

Переваримость питательных веществ была изучена в ходе балансовых опытов. В учётный период, в ходе которого проведён учёт съеденных кормов и их остатков, были собраны средние пробы кала (10 \%) и мочи (3\%) от общего количества в сутки, проведены исследования по методикам зоотехнического анализа (Лукашик А.А. и Тащилин В.А., 1965). Зоотехнические анализы были проведены в Испытательном центре Федерального научного центра биологических систем и агротехнологий РАН. В пробах кала определяли массовую долю сухого вещества, сырого протеина (ГОСТ 13496.4-93), массовую долю сырого жира (ГОСТ 13496.15-97), массовую долю сырой клетчатки (ГОСТ 12396.2-91), массовую долю сырой золы (ГОСТ 26226-95), кальция (ГОСТ 26570-95), фосфора (ГОСТ 26657-97). Минеральный состав кала: медь, кадмий, свинец, железо, цинк, марганец, кобальт определяли по ГОСТ 30178-96.

В пробах мочи (3 \% от общего количества) определяли удельный вес, минеральные вещества, содержание азота по П.Т. Лебедеву, А.Т. Усовичу (1976). Сравнительную характеристику эффективности усвоения азота изучали путём расчёта коэффициентов использования этого элемента от принятого и переваренного.

Обмен энергии в организме подопытных животных определяли по учебно-методическому пособию Левахина В.И. и др. (2016).

Оборудование и технические средства. Шкаф сушильный ШС-80-01 СПУ зав. № 27919 («Смоленское СПТБ СПУ», Россия), электропечь СНОЛ1.6.2.5.1/9-ИЗ зав. № 1761 (завод электропечей, г. Утенск, Россия), весы лабораторные ВЛТ-150П зав. № 108688875 (3АО «Сартогосм», г. Санкт-Петербург, Россия), комплекс для определения белка, азота модель UDK 139 UDK 139 («Velp», Италия).

Статистическая обработка. Данные представлены в виде средних значений \pm стандартная ошибка средней. Статистический анализ проводили с помощью офисного программного комплекса «Microsoft Office» с применением программы «Excel» («Microsoft», США) с обработкой данных в «Statistica 10.0» («Stat Soft Inc.», США).

\section{Результаты исследования.}

Переваримость питательных веществ подопытными животными. Исследования влияния ВДЧ $\mathrm{SiO}_{2}$ и $\mathrm{FeCo}$ на переваримость питательных веществ выявили ряд различий в эффективности использования корма. Так, переваримость сухого вещества была увеличена в I опытной группе на $1,76 \%$ (P $\leq 0,01)$, во II - на $1 \%$ относительно контроля. Повышение коэффициента переваримости органического вещества составило $1,7 \%(\mathrm{P} \leq 0,01)$ и $1 \%$ ( $\mathrm{P} \leq 0,05)$ (табл. 1$)$.

Значения переваримости сырого протеина увеличились в I, II опытных группах на $2,7 \%$ $(\mathrm{P} \leq 0,01)$ и на $1,3 \%(\mathrm{P} \leq 0,01)$ соответственно. Переваримость сырого жира в сравнении с контролем оказалась выше во II опытной группе на $2,9 \%$ (P $\leq 0,01)$. Коэффициент переваримости сырой клетчатки повышался в I и II опытных группах на $2,7 \%$ (P $\leq 0,01)$ и на 1,87 \% (P $\leq 0,01)$. Аналогичное повышение переваримости отмечалось нами и для безазотистых экстрактивных веществ. 
Таблица 1. Коэффициенты переваримости питательных веществ рационов у подопытных животных, \%

Table 1. The digestibility ratios of nutrients from diets of experimental animals, \%

\begin{tabular}{|l|c|c|c|}
\hline \multirow{2}{*}{\multicolumn{1}{|c|}{ Показатель/Indicator }} & \multicolumn{3}{|c|}{ Группа/Group } \\
\cline { 2 - 4 } & $\begin{array}{c}\text { I опытная / } \\
\text { I experimental }\end{array}$ & $\begin{array}{c}\text { II опытная/ } \\
\text { II experimental }\end{array}$ & $\begin{array}{c}\text { контрольная/ } \\
\text { control }\end{array}$ \\
\hline Сухое вещество/Dry matter & $65,73 \pm 0,17 * *$ & $64,53 \pm 0,27$ & $63,97 \pm 0,08$ \\
Органическое вещество/Organic matter & $68,57 \pm 0,18^{* *}$ & $67,43 \pm 0,17 *$ & $66,83 \pm 0,17$ \\
Сырой протеин/Crude protein & $64,57 \pm 0,02 * *$ & $63,09 \pm 0,18^{* *}$ & $61,80 \pm 0,15$ \\
Сырой жир/Crude fat & $68,10 \pm 0,55$ & $70,64 \pm 0,02 * *$ & $67,73 \pm 0,46$ \\
Сырая клетчатка/Crude fiber & $54,49 \pm 0,24 * *$ & $53,67 \pm 0,08 * *$ & $51,80 \pm 0,10$ \\
БЭВ/ Nitrogen-free extractive substances & $73,30 \pm 0,70$ & $74,70 \pm 0,11^{* *}$ & $71,70 \pm 0,06$ \\
\hline
\end{tabular}

Примечание: * - $\mathrm{P} \leq 0,05 ; * *-\mathrm{P} \leq 0,01$

Note: ${ }^{*}-\mathrm{P} \leq 0.05 ; * *-\mathrm{P} \leq 0.01$

Таким образом, наиболее высокими показателями переваримости большинства питательных веществ обладали бычки, получавшие ВДЧ $\mathrm{SiO}_{2}$.

Обмен энергии и азота в организме подопытных животных. Рассмотрение обмена энергии в организме подопытных бычков выявило изменения в эффективности процессов на этапе пищеварения и межуточного обмена. Введение ВДЧ оказало влияние на эффективность превращения энергии корма в организме подопытных бычков (табл. 2).

Поступление энергии в организм было практически одинаковым. Переваримой энергии бычки потребляли больше в I и II группе на 2,9 \% (P $\leq 0,01)$ и на $3,1 \%$ ( $\leq 0,01)$ относительно контроля. Обменная энергия в I и II группах превосходила контрольную группу на 12 и 2 МДж.

\section{Таблица 2. Потребление питательных веществ и характер использования энергии подопытными животными \\ Table 2. Nutrient intake and energy use of experimental animals}

\begin{tabular}{|c|c|c|c|}
\hline \multirow[b]{2}{*}{ Показатель/Indicator } & \multicolumn{3}{|c|}{ Группа/Group } \\
\hline & $\begin{array}{l}\text { I опытная/ } \\
\text { I experimental }\end{array}$ & $\begin{array}{c}\text { II опытная/ } \\
\text { II experimental }\end{array}$ & $\begin{array}{l}\text { контроль- } \\
\text { ная/control }\end{array}$ \\
\hline Валовая энергия, МДж/Gros & $122,12 \pm 0,011$ & $122,13 \pm 0,002$ & $122,08 \pm 0,041$ \\
\hline Переваримая энергия, МДж/Digestible energy, MJ & $76,92 \pm 0,033 * *$ & $77,09 \pm 0,080 * *$ & $74,75 \pm 0,134$ \\
\hline Обменная энергия, МДж/Exchange energy, МJ & $71,72 \pm 5,192$ & $61,62 \pm 0,063 * *$ & $59,69 \pm 0,103$ \\
\hline $\begin{array}{l}\text { Обменная энергия на продукцию, МДж/ Exchange } \\
\text { energy for products, MJ }\end{array}$ & $39,72 \pm 6,700$ & $29,52 \pm 0,465$ & $30,03 \pm 0,231$ \\
\hline Чистая энергия прироста, МДж/Net growth energy, MJ & $12,83 \pm 2,164$ & $9,58 \pm 0,148$ & $9,44 \pm 0,056$ \\
\hline КПИ ОЭ, \%/ CUE ME, \% & $32,30 \pm 0,000 * *$ & $32,45 \pm 0,033 * *$ & $31,44 \pm 0,054$ \\
\hline
\end{tabular}

Примечание: * - $\mathrm{P} \leq 0,05 ; * *-\mathrm{P} \leq 0,01$

Note: $*-\mathrm{P} \leq 0.05 ; * *-\mathrm{P} \leq 0.01$

Коэффициент продуктивного использования обменной энергии в I и II группах был больше на $1 \%$ в отношении контрольной группы.

Характеризуя белковый обмен на этапе переваривания и всасывания компонентов, следует обратиться к балансу азота в организме. На основании проведённого эксперимента установлено, что у всех подопытных бычков баланс азота был положительным, а эффективность была разной (табл. 3). 
Таблица 3. Среднесуточный баланс азота у подопытных животных, г Table 3 . The average daily nitrogen balance of experimental animals, $g$

\begin{tabular}{|l|c|c|c|}
\hline \multicolumn{1}{|c|}{ Показатели/Indices } & $\begin{array}{c}\text { I опытная / } \\
\text { I experimental }\end{array}$ & $\begin{array}{c}\text { II опытная/ } \\
\text { II experimental }\end{array}$ & $\begin{array}{c}\text { контрольная/ } \\
\text { соntrol }\end{array}$ \\
\hline Принято/Received & $167 \pm 0,12^{* *}$ & $165 \pm 0,12$ & $163 \pm 0,20$ \\
Выделено в кале/Excreted with feces & $49,1 \pm 3,22$ & $44,1 \pm 2,73$ & $55,7 \pm 0,83$ \\
Выделено в моче/Excreted with urine & $82,1 \pm 0,91$ & $78,5 \pm 1,00$ & $85,9 \pm 0,73$ \\
Переварено/Digested & $118 \pm 3,27^{*}$ & $121 \pm 1,04^{* *}$ & $107 \pm 0,85$ \\
Отложено на 1 гол./Deposited per a head & $36,3 \pm 3,55^{*}$ & $42,8 \pm 1,69^{* *}$ & $21,5 \pm 0,17$ \\
Отложено на 100 кг жив. мас./ & $10,9 \pm 1,10^{*}$ & $12,8 \pm 0,47^{* *}$ & $6,46 \pm 0,07$ \\
$\begin{array}{l}\text { Deposited per 100 kg of live weight } \\
\text { Коэф.испол.от принятого, \%/ Utilization } \\
\text { соеfficient from the received, \% }\end{array}$ & $21,7 \pm 2,11^{*}$ & $25,8 \pm 1,03^{* *}$ & $13,1 \pm 0,09$ \\
Коэф.испол. от переваренного, \%/ & & & \\
Utilization coefficient from the digested, \% & $30,6 \pm 2,19^{*}$ & $35,3 \pm 1,71^{* *}$ & $20,0 \pm 0,20$ \\
\hline
\end{tabular}

Примечание: * $-\mathrm{P} \leq 0,05 ; * *-\mathrm{P} \leq 0,01$.

Note: * $-\mathrm{P} \leq 0.05 ; * *-\mathrm{P} \leq 0.01$.

Наибольшее поступление азота отмечено в I и II опытных группах 165,0-167 г/гол./сут, что согласуется с болышим уровнем потребления корма животными опытных групп. Так, животные I и II групп переваривали азот на 10,3\% $(\mathrm{P} \leq 0,05)$ и $13,1 \%(\mathrm{P} \leq 0,01)$ интенсивнее относительно контроля. Лидирующую позицию занимала II группа, в которой коэффициент использования азота от принятого был выше на 12,7 \% по сравнению с контрольной и I опытной группами, а коэффициент использования азота от переваренного - на 76,5 \% $(\mathrm{P} \leq 0,01)$ и 15,4 \% $(\mathrm{P} \leq 0,01)$ соответственно.

\section{Обсуждение полученных результатов.}

Опыт применения кормовых добавок в форме ВДЧ в кормлении животных в настоящее время расширяется (Сизова Е.А. и Яушева Е.В., 2019). Это подтверждается анализом рынка кормовых добавок, проведённого Американской ассоциацией производителей кормов (AFIA) (Pietroiusti A et al., 2016).

Для обеспечения высокопродуктивной жизнедеятельности необходимо постоянное пополнение затрат энергии (Курилкина М.Я. и др., 2017). Обменная энергия используется для поддержания процессов жизнедеятельности организма и формирования продуктивности (Атландерова К.Н. и др., 2018). Высокая эффективность использования энергии и азота животных отмечена во II опытной группе, потреблявшей ВДЧ FеCо.

Доказано, что внесение в рацион микроэлементов положительно влияет на показатели роста, переваримость и усвояемость энергии и белка (Espinosa CD et al., 2019), а также на минеральный обмен (Сизова Е.А., 2017б). Введение в рацион животных кобальта улучшает физиологобиохимические показатели и повышает продуктивность крупного рогатого скота и кроликов (Назарова А.А. и Полищук С.Д., 2009). Железо в сочетании с кобальтом стимулирует рост животных, повышает переваримость компонентов корма (Miroshnikova E et al., 2015). Перевариваемость сухого вещества, органического вещества, сырого протеина увеличивается при добавлении селена (Alimohamady R et al., 2013). Различные формы цинка улучшают показатели роста за счёт увеличения удержания азота и усвояемости жира у растущих норок (Cui H et al., 2017). Перевариваемость целлюлозы увеличивается только после применения микроэлементов (Zelenák I et al., 1992).

В нашем эксперименте наиболее высокими показателями переваримости большинства питательных веществ обладали бычки, получавшие ВДЧ $\mathrm{SiO}_{2}$. Возможно, фактором, определяющим повышение переваримости, является изменение разнообразия и функциональной активности микробиоты рубца (Макаева A.M. и др., 2019; Makaeva AM et al., 2019). Микроэлементы, поступая в рубец, поглощаются симбионтными микроорганизмами, число которых при введении минераль- 
ных добавок увеличивается, а следовательно, растёт их ферментативная активность. Соединение различных механизмов действия бактериальных и грибных целлюлаз приводит к повышению эффективности переваривания клетчатки в рубце (Arelovich HM et al., 2000). Включаясь в процесс рубцового пищеварения, микроорганизмы тесно взаимодействуют с растительным материалом (Huws SA et al., 2018). В свою очередь микроорганизмы рубца могут влиять на метаболизм других питательных веществ, таких как азот и сера (Veira DM, 1986).

Важным показателем эффективности использования рационов животными является влияние используемых добавок на отложение азота в организме животных (Дускаев Г.К. и Каримов И.Ф., 2018). Степень использования азота определяется в основном возрастом и направлением продуктивности животного, а также условиями кормления и содержанием (Рахимжанова И.А. и др., 2012). Скармливание минеральных добавок положительно сказалось на отложении азота в теле животных. В наших исследованиях баланс азота в организме опытных животных находился в пределах 20-35 \%, одной из причин высокого использования растительного белка в наших исследованиях являлись минеральные комплексы, входящие в состав рациона. Возможно, кремний активизирует белковый обмен, усиливает доставку аминокислот к органам и тканям и ускоряет формирование мышечной ткани и в целом, что согласуется с ранее проведёнными исследованиями (Пентюк А.А. и Луцюк Н.Б., 2003; Боголюбова Н.В. и др., 2015), демонстрирующими перспективы использования кремния в питании животных.

\section{Выводы}

Скармливание животным микроэлементов в форме ВДЧ сопровождается повышением коэффициентов переваримости питательных веществ рационно, с выраженным эффектом для $\mathrm{SiO}_{2}$.

\section{Работа выполнена в рамках исследований по проекту № 18-8-9-19}

\section{Литература}

1. Атландерова К.Н., Макаева А.М., Курилкина М.Я. Перспективы использования ультрадисперсных частиц в кормлении молодняка крупного рогатого скота // Нанотехнологии в сельском хозяйстве: перспективы и риски: материалы междунар. науч.-практ. конф. (г. Оренбург, 26-27 сент. 2018 г.) / под общ. ред. чл.-корр. РАН С.А. Мирошникова. Оренбург: Изд-во ФГБНУ ФНЦ БСТ PAH, 2018. C. 46-50. [Atlanderova KN, Makaeva AM, Kurilkina MYa. Perspektivy ispol'zovaniya ul'tradispersnykh chastits $\mathrm{V}$ kormlenii molodnyaka krupnogo rogatogo skota. (Conference proceedigs) Nanotekhnologii v sel'skom khozyaistve: perspektivy i riski: materialy mezhdunar. nauch.-prakt. konf. g. Orenburg, 26-27 sent. 2018 g.). pod obshch. red. chl.-korr. RAN. Miroshnikova SA. Orenburg: Izd-vo FGBNU FNTs BST RAN;2018:46-50. (In Russ)].

2. Боголюбова Н.В., Романов В.Н., Девяткин В.А. Процессы пищеварения и переваримость питательных веществ у овец при использовании минерала шунгит как источника эрготропных соединений // Известия Самарской государственной сельскохозяйственной академии. 2015. № 1. C. 168-171. [Bogolubova NV, Romanov VN, Devyatkin VA. The processes of sheep digestion and digestibility of nutrients using mineral shungite as ergotropic substances source. Bulletin Samara State Agricultural Academy. 2015;1:168-171. (In Russ)].

3. Венедиктов А.М. Применение макроэлементов в кормлении крупного рогатого скота // Справочник по кормовым добавкам. Минск: Ураджай, 1990. С. 142-149. [Venediktov AM. Primenenie makroelementov $\mathrm{v}$ kormlenii krupnogo rogatogo skota. Spravochnik po kormovym dobavkam. Minsk: Uradzhai; 1990:142-149. (In Russ)].

4. Воздействие высокодисперсных частиц металлов на переваримость питательных веществ и обмен энергии в организме молодняка крупного рогатого скота / М.Я. Курилкина, Т.Н. Холодилина, Д.М. Муслюмова, К.Н. Атландерова, О.А. Завьялов // Вестник мясного скотоводства. 2017. № 4(100). С. 197-201. [Kurilkina MYa, Kholodilina TN, Muslyumova DM, Atlanderova KN, Zavyalov OA. The effect of finely dispersed metal particles on the digestibility of nutrients and energy exchange in the body of young cattle. Herald of Beef Cattle Breeding. 2017;4(100):197-201. (In Russ)]. 
5. Дускаев Г.К., Каримов И.Ф. Некоторые рекомендации и разработки для использования в кормлении крупного рогатого скота // Мясное скотоводство - приоритеты и перспективы развития: материалы междунар. науч.-практ. конф. / под ред. чл-корр. РАН С.А. Мирошникова. Оренбург: Изд-во ФГБНУ ФНЦ БСТ РАН, 2018. С. 167-175. [Duskaev GK, Karimov IF. Nekotorye rekomendatsii i razrabotki dlya ispol'zovaniya $\mathrm{v}$ kormlenii krupnogo rogatogo skota. (Conference proceedigs) Myasnoe skotovodstvo - prioritety i perspektivy razvitiya: materialy mezhdunar. nauch.-prakt. konf. pod red. S.A. Miroshnikova. Orenburg: Izd-vo FGBNU FNTs BST RAN. 2018:167-175. (In Russ)].

6. Изменение бактериального сообщества в желудочно-кишечном тракте кур в онтогенезе / В.И. Фисинин, Г.Ю. Лаптев, И.Н. Никонов, Л.А. Ильина, Е.А. Йылдырым, В.А. Филиппова, Н.И. Новикова, А.А. Грозина, Т.А. Егорова, Т.Н. Ленкова, В.А. Манукян, И.А. Егоров // Сельскохозяйственная биология. 2016. Т. 51. 6. С. 883-890. doi: 10.15389/agrobiology.2016.6.883rus [Fisinin VI, Laptev GYu, Nikonov IN, Il'ina LA, Yildirim EA, Filippova VA, Novikova NI, Grozina AA, Egorova TA, Lenkova TN, Manukyan VA, Egorov IA. Poultry gastrointestinal microbiome changes during ontogenesis. Agricultural Biology (Sel'skokhozyaistvennaya Biologiya). 2016;51(6):883-890. (In Russ)]. doi: 10.15389/agrobiology.2016.6.883eng

7. Исследование наночастиц металлов в качестве источника микроэлементов для животных / Е.В. Яушева, А.Г. Зелепухин, Н.И. Рябов, О.В. Кван, В.А. Раменский, А.Х. Заверюха, Ф.Х. Сиразетдинов // Современные проблемы науки и образования. 2013. № 5. С. 470. [Yausheva EV, Zelepukhin AG, Ryabov NI, Kvan OV, Ramenskii VA, Zaveryukha AH, Sirazetdinov FH. Study of metal nanoparticlesas a source of micronutrient for animals. Modern Problems of Science and Education. 2013;5:470. (In Russ)].

8. Кальницкий Б.Д. Эффективность применения минеральной смеси и тесты для контроля обеспеченности животных минеральными элементами // Справочник по кормовым добавкам. Минск: Ураджай, 1990. С. 190-194. [Kal'nitskii B.D. Effektivnost' primeneniya mineral'noi smesi i testy dlya kontrolya obespechennosti zhivotnykh mineral'nymi elementami. Spravochnik po kormovym dobavkam. Minsk: Uradzhai; 1990:190-194. (In Russ)].

9. Лебедев П.Т., Усович А.Т. Методы исследования кормов, органов и тканей животных. 3-е изд., перераб. и доп. М.: Россельхозиздат. 1976. 389 с. [Lebedev PT, Usovich AT. Metody issledovaniya kormov, organov i tkanei zhivotnykh. 3-e izd., pererab. i dop. Moskva: Rossel'khozizdat; 1976: 389 p. (In Russ)].

10. Лукашик А.А., Тащилин В.А. Зоотехнический анализ кормов: практикум. М.: Колос. 1965. 225 с. [Lukashik AA, Tashchilin VA. Zootekhnicheskii analiz kormov: practicum. Moscow: Kolos; 1965:225 p. (In Russ)].

11. Назарова А.А, Полищук С.Д. Влияние нанокристаллического железа на минеральный обмен в организме животных: сб. тез. докл. участников Второго межд. конкурса науч. работ молодых учёных в области нанотехнологий. М., 2009. С. 790-792. [Nazarova AA, Polishchuk SD. Vliyanie nanokristallicheskogo zheleza na mineral'nyi obmen v organizme zhivotnykh: sb. Tez. dok1. uchastnikov Vtorogo mezhd. konkursa nauch. rabot molodykh uchenykh v oblasti nanotekhnologii. Moscow. 2009;790-792. (In Russ)].

12. Пентюк А.А., Луцюк Н.Б. Токсикологические исследования силикса // Медицинская химия и клиническое применение диоксида кремния. Київ: Наукова Думка, 2003. С. 180-202. [Pentyuk AA, Lutsyuk NB. Toksikoloricheskie issledovaniya siliksa. Meditsinskaya khimiya i klinicheskoe primenenie dioksida kremniya. Kiïv: Naukova Dumka; 2003:180-202. (In Russ)].

13. Пособие для проведения научно-исследовательских работ в зоотехнии: учеб. пособие / В.И. Левахин, Н.А. Балакирев, А.В. Харламов, Г.И. Левахин и др. Оренбург, 2016. 227 с. [Levakhin VI, Balakirev NA, Kharlamov AV, Levakhin GI, et al. Posobie dlya provedeniya nauchnoissledovatel'skikh rabot v zootekhnii: ucheb. posobie. Orenburg. 2016:227 p. (In Russ)].

14. Рахимжанова И.А., Левахин В.И., Галиев Б.Х. Энергетический обмен в организме бычков при использовании ростстимулирующего препарата Орего-стим в рационе // Известия Оренбургского государственного аграрного университета. 2012. № 6(38). С. 118-120. [Rakhim- 
zhanova IA, Levakhin VI, Galiev BKh. Energy metabolism in the organism of bull-calves fed the growth stimulating preparation. Izvestia Orenburg State Agrarian University.2012;6(38):118-120. (In Russ)].

15. Сизова Е.А., Бирюкова М.С., Данилова Ю.С. Эффективность применения наноразмерных форм микроэлементов в кормлении цыплят-бройлеров // Нанотехнологии в сельском хозяйстве: перспективы и риски: сб. науч. тр. по материалам межд. науч.-практ. конф. Оренбург; Издво ФНЦ БСТ РАН, 2018. С. 145-149. [Sizova EA, Biryukova MS, Danilova YuS. The efficacy of nano forms of trace elements in the feeding of broiler chickens. Conference proceedigs) Nanotekhnologii v sel'skom khozyaistve: perspektivy i riski: materialy mezhdunar. nauch.-prakt. konf. g. Orenburg, 26-27 sent. 2018 g.). pod obshch. red. chl.-korr. RAN. Miroshnikova SA. Orenburg: Izd-vo FGBNU FNTs BST RAN;2018:145-149. (In Russ)].

16. Сизова Е.А., Яушева Е.В. Сравнительная продуктивность цыплят-бройлеров при инъекционном введении разноразмерных ультрадисперсных частиц железа // Животноводство и кормопроизводство. 2019. Т. 102. № 1. С. 6-21. [Sizova EA, Yausheva EV. Comparative productivity of broiler chickens injected with variously sized ultrafine iron particles. Animal Husbandry and Fodder Production. 2019;102(1):6-21. (In Russ)]. doi: 10.33284/2658-3135-102-1-6

17. Сизова Е.А. Сравнительная характеристика биологических эффектов разноразмерных наночастиц меди и железа // Вестник российской сельскохозяйственной науки. 2017а. № 3. C. 13-17. [Sizova EA. Comparative analysis of the different-sized copper and iron nanoparticles biological effects. Vestnik of the Russian Agricultural Science. 2017a;3:13-17. (In Russ)].

18. Сизова Е.А. Влияние включения в рацион наночастиц меди на уровень кадмия в организме цыплят-бройлеров // Вестник мясного скотоводства. 2017б. № 1(97). С. 13-20. [Sizova EA. Effect of copper nanoparticles in traduced to the diet on cadmium level of broiler chickens. Herald of Beef Cattle Breeding. 2017b;1(97):13-20. (In Russ)].

19. Сравнительное исследование ранозаживляющего действия веществ различной природы / О.А. Богословская, Т.А. Байтукалов, Н.Н. Глущенко, А.С. Шеремет, И.П. Ольховская, Т.А. Лобаева, С.А. Лопатин, В.П. Варламов // Естественные и технические науки. 2007. № 6(32). С. 91-99. [Bogoslovskaya OA, Baitukalov TA, Glushchenko NN, Sheremet AS, Ol'khovskaya IP, Lobaeva TA, Lopatin SA, Varlamov VP. Sravnitel'noe issledovanie ranozazhivlyayushchego deistviya veshchestv razlichnoi prirody. Natural and Technical sciences. 2007;6(32):91-99. (In Russ)].

20. Элементный и микроэкологический состав рубца при использовании в кормлении крупного рогатого скота высокодисперсных частиц / А.М. Макаева, К.Н. Атландерова, Е.А. Сизова, С.А. Мирошников, В.В. Ваншин // Животноводство и кормопроизводство. 2019. Т. 102. № 3. C. 19-32. [Makaeva AM, Atlanderova KN, Sizova EA, Miroshnikov SA, Vanshin VV. The elemental and microecological composition of rumen after use of highly dispersive particles in cattle feeding. Animal Husbandry and Fodder Production. 2019;102(3):19-32. (In Russ)]. doi: 10.33284/2658-3135-102-3-19

21. Alimohamady R, Aliarabi H, Bahari A, Dezfoulian AH. Influence of different amounts and sources of selenium supplementation on performance, some blood parameters, and nutrient digestibility in lambs. Biological Trace Element Research. 2013;154(1):45-54. doi: https://doi.org/10.1007/s12011013-9698-4

22. Arelovich HM, Owens FN, Horn GW, Vizcarra JA. Effects of supplemental zinc and manganese on ruminal fermentation, forage intake, and digestion by cattle fed prairie hay and urea. Journal of Animal Science. 2000;78(11):2972-2979. doi: https://doi.org/10.2527/2000.78112972x

23. Bergmann GT. Microbial community composition along the digestive tract in forage- and grain-fed bison. BMC Vet Res. 2017;13(1):253. doi: 10.1186/s12917-017-1161-x.

24. Cui H, Zhang TT, Nie H, Wang ZC, Zhang XL, Shi B, Yang FH, Gao XH. Effects of sources and concentrations of zinc on growth performance, nutrient digestibility, and fur quality of growing-furring female mink (Mustela vison). J Anim Sci. 2017;95(12):5420-5429. doi: https://doi.org/10.2527/jas2017.1810

25. Espinosa CD, Fry RS, Kocher ME, Stein HH. Effects of copper hydroxychloride and distillers dried grains with solubles on intestinal microbial concentration and apparent ileal and total 
tract digestibility of energy and nutrients by growing pigs. J Anim Sci. 2019;97(12):4904-4911. doi: 10.1093/jas/skz340.

26. Fondevila M, Herrer RM, Casallas MC, Abecia L, Ducha JJ. Silver nanoparticles as a potential antimicrobial additive for weaned pigs. Animal Feed Science and Technology. 2009;150(3-4):259269. doi: https://doi.org/10.1016/j.anifeedsci.2008.09.003

27. Gorlov IF, et al. Effect of feeding with organic microelement complex on blood composition and beef production of young cattle. Modern Applied Science. 2015;9(10):8-16. doi:10.5539/mas.v9n10p8

28. Henderson G, Cox F, Ganesh S, Jonker A, Young W, Global Rumen Census C, Janssen PH. Rumen microbial community composition varies with diet and host, but a core microbiome is found across a wide geographical range. Sci. Rep. 2015;5:14567. doi: 10.1038/srep14567

29. Huws SA, Creevey CJ, Oyama LB, Mizrahi I, Denman SE, Popova M, et al. Addressing global ruminant agricultural challenges through understanding the rumen microbiome: past, present, and future. Front Microbiol. 2018. 25(9):2161. doi: 10.3389/fmicb.2018.02161

30. Makaeva A, Atlanderova K, Miroshnikov S, Sizova E. Rumen microbiome of cattle after introduction of ultrafine particles in feed. FEBS Open Bio. 2019;9(S1):416.

31. Miroshnikova E, Arinzhanov A, Kilyakova Y, Sizova E, Miroshnikov S. Antagonist metal alloy nanoparticles of iron and cobalt: impact on trace element metabolism in carp and chicken. Human \& Veterinary Medicine. International Journal of the Bioflux Society. 2015;7(4):253-259.

32. Pietroiusti A, Magrini A, Campagnolo L. New frontiers in nanotoxicology: Gut microbiota/microbiome-mediated effects of engineered nanomaterials. Toxicol Appl Pharmacol. 2016;299:90-95. doi: https://doi.org/10.1016/j.taap.2015.12.017

33. Prasad R, Bhattacharyya A, Nguyen D. Quang nanotechnology in sustainable agriculture: recent developments, challenges, and perspectives. Front Microbiol. 2017;8:1014. doi: $10.3389 /$ fmicb.2017.01014

34. Rosenberg E, DeLong EF, Lory S, Stackebrandt E, Thompson F, editors. The Prokaryotes: Prokaryotic Biology and Symbiotic Associations. 4th ed. Springer-Verlag Berlin Heidelberg; 2013: $607 \mathrm{p}$.

35. Torok VA, Percy NJ, Moate PJ, Ophel-Keller K. Influence of dietary docosahexaenoic acid supplementation on the overall rumen microbiota of dairy cows and linkages with production parameters. Can J Microbiol. 2014;60(5):267-275. doi: 10.1139/cjm-2013-0805

36. Veira DM. The role of ciliate protozoa in nutrition of the ruminant Journal of Animal Science. 1986;63(5):1547-1560.

37. Walsh $\mathrm{K}$ et al. Intake, digestibility and rumen characteristics in cattle offered whole-crop wheat or barley silages of contrasting grain to straw ratios. Anim Feed Sci Tech. 2009;148(2):192-213. doi: 10.1016/j.anifeedsci.2008.03.013

38. Wang MQ, Wang C, Li H, Du YJ, Tao WJ, Ye SS, He YD. Effects of chromium-loaded chitosan nanoparticles on growth, blood metabolites, immune traits and tissue chromium in finishing pigs. Biol Trace Elem Res. 2012;149(2):197-203. doi: 10.1007/s12011-012-9428-3

39. Wang MQ, Wang C, Li H, Du YJ, Tao WJ, Ye SS, He YD. Effects of chromium-loaded chitosan nanoparticles on growth, carcass characteristics, pork quality, and lipid metabolism in finishing pigs. Livest Sci. 2014;161:123-129. doi: 10.1016/j.livsci.2013.12.029

40. Wang C, Wang MQ, Ye SS, Tao WJ, Du YJ. Effects of copper-loaded chitosan nanoparticles on growth and immunity in broilers. Poult Sci. 2011;90(10): 2223-2228. doi: https://doi.org/10.3382/ps.2011-01511

41. Zeineldin M, Barakat R, Elolimy A, Salem AZM, Elghandour MMY, Monroy JC. Synergetic action between the rumen microbiota and bovine health. Microb Pathog. 2018;124:106-115. doi: https://doi.org/10.1016/j.micpath.2018.08.038

42. Zelenák I, Jalc D, Plachá I, Sviatko P, Vendrák T, Siroka P, Gyulai F. The effect of copper and cobalt supplementation on the digestibility of fibrous feed in sheep. Vet Med (Praha). 1992;37(4):221-229. 
43. Zhu W, et al. Effects of dietary forage sources on rumen microbial protein synthesis and milk performance in early lactating dairy cows. J Dairy Sci. 2013;96(3):1727-1734. doi: $10.3168 /$ jds. $2012-5756$

\section{References}

1. Atlanderova KN, Makaeva AM, Kurilkina MYa. Prospects for the use of ultrafine particles in the feeding of young cattle. (Conference proceedigs) Nanotechnology in agriculture: prospects and risks: international materials. scientific-practical conf. (Orenburg, September 26-27. 2018). under total. ed. Corr. Mem. RAS Miroshnikov SA. Orenburg: Publishing House FRS BST RAS; 2018: 46-50.

2. Bogolubova NV, Romanov VN, Devyatkin VA. The processes of sheep digestion and digestibility of nutrients using mineral shungite as ergotropic substances source. Bulletin Samara State Agricultural Academy. 2015;1:168-171.

3. Venediktov AM. The use of macronutrients in feeding cattle. Handbook of forage-vym additives.. Minsk: Uradzhai; 1990:142-149. (In Russ)].

4. Kurilkina MYa, Kholodilina TN, Muslyumova DM, Atlanderova KN, Zavyalov OA. The effect of finely dispersed metal particles on the digestibility of nutrients and energy exchange in the body of young cattle. Herald of Beef Cattle Breeding. 2017;4(100):197-201.

5. Duskaev GK, Karimov IF. Some recommendations and developments for use in feeding cattle. (Conference proceedigs) Beef cattle breeding - priorities and development prospects: international materials. Scientific-Practical Conf. (Orenburg, April 25-26, 2018). edited by Corr. Memb SA Miroshnikov. Orenburg: Publishing House of the Federal Research Center of BST RAS; 2018:167-175.

6. Fisinin VI, Laptev GYu, Nikonov IN, Il'ina LA, Yildirim EA, Filippova VA, Novikova NI, Grozina AA, Egorova TA, Lenkova TN, Manukyan VA, Egorov IA. Poultry gastrointestinal microbiome changes during ontogenesis. Agricultural Biology (Sel'skokhozyaistvennaya Biologiya). 2016;51(6):883 890. doi: 10.15389/agrobiology.2016.6.883eng

7. Yausheva EV, Zelepukhin AG, Ryabov NI, Kvan OV, Ramenskii VA, Zaveryukha AH, Sirazetdinov FH. Study of metal nanoparticlesas a source of micronutrient for animals. Modern Problems of Science and Education. 2013;5:470.

8. Kal'nitskii B.D. The effectiveness of the use of mineral mixtures and tests to control the supply of animals with mineral elements // Handbook of feed additives. Mn.: Uradzhai; 1990: 190-194.

9. Lebedev PT, Usovich AT. Methods for the study of animal feed, organs and tissues: 3rd ed., Revised. and add. Moscow: Rosselkhozizdat; 1976: 389 p.

10. Lukashik AA, Tashchilin VA. Zootechnical analysis of feed. Workshop. Moscow: Kolos; 1965: 225 p.

11. Nazarova AA, Polishchuk SD. The effect of nanocrystalline iron on mineral metabolism in animals (Conference proceedigs). Sat. thesis. doc. participants of the Second Int. competition scientific. works of young scientists in the field of nanotechnology. Moscow. 2009; 790-792.

12. Pentyuk AA, Lutsyuk NB. Toxicological studies of silicon. Medical chemistry and clinical use of silicon dioxide. Kiïv: Naukova Dumka; 2003: 180-202.

13. Levakhin VI, Balakirev NA, Kharlamov AV, Levakhin GI, et al. The allowance for research in zootechnology: textbook. allowance. Orenburg. 2016: 227 p.

14. Rakhimzhanova IA, Levakhin VI, Galiev BKh. Energy metabolism in the organism of bull-calves fed the growth stimulating preparation. Izvestia Orenburg State Agrarian University.2012;6(38):118-120.

15. Sizova EA, Biryukova MS, Danilova YuS. The efficacy of nano forms of trace elements in the feeding of broiler chickens. (Conference proceedigs) Nanotechnology in agriculture: prospects and risks: international materials. scientific-practical conf. (Orenburg, September 26-27. 2018). under total. ed. Corr. Mem. RAS Miroshnikov SA. Orenburg: Publishing House FRS BST RAS; 2018: 145-149.

16. Sizova EA, Yausheva EV. Comparative productivity of broiler chickens injected with variously sized ultrafine iron particles. Animal Husbandry and Fodder Production. 2019;102(1):6-21. doi: 10.33284/2658-3135-102-1-6 
17. Sizova EA. Comparative analysis of the different-sized copper and iron nanoparticles biological effects. Vestnik of the Russian Agricultural Science. 2017a;3:13-17.

18. Sizova EA. Effect of copper nanoparticles in traduced to the diet on cadmium level of broiler chickens. Herald of Beef Cattle Breeding. 2017b;1(97):13-20.

19. Bogoslovskaya OA, Baitukalov TA, Glushchenko NN, Sheremet AS, Ol'khovskaya IP, Lobaeva TA, Lopatin SA, Varlamov VP. A comparative study of the wound healing effect of substances of various nature. Natural and Technical sciences. 2007;6(32):91-99.

20. Makaeva AM, Atlanderova KN, Sizova EA, Miroshnikov SA, Vanshin VV. The elemental and microecological composition of rumen after use of highly dispersive particles in cattle feeding. Animal Husbandry and Fodder Production. 2019;102(3):19-32. (In Russ)]. doi: 10.33284/2658-3135-1023-19

21. Alimohamady R, Aliarabi H, Bahari A, Dezfoulian AH. Influence of different amounts and sources of selenium supplementation on performance, some blood parameters, and nutrient digestibility in lambs. Biological Trace Element Research. 2013;154(1):45-54. doi: https://doi.org/10.1007/s12011013-9698-4

22. Arelovich HM, Owens FN, Horn GW, Vizcarra JA. Effects of supplemental zinc and manganese on ruminal fermentation, forage intake, and digestion by cattle fed prairie hay and urea. Journal of Animal Science. 2000;78(11):2972-2979. doi: https://doi.org/10.2527/2000.78112972x

23. Bergmann GT. Microbial community composition along the digestive tract in forage- and grain-fed bison. BMC Vet Res. 2017;13(1):253. doi: 10.1186/s12917-017-1161-x.

24. Cui H, Zhang TT, Nie H, Wang ZC, Zhang XL, Shi B, Yang FH, Gao XH. Effects of sources and concentrations of zinc on growth performance, nutrient digestibility, and fur quality of growing-furring female mink (Mustela vison). J Anim Sci. 2017;95(12):5420-5429. doi: https://doi.org/10.2527/jas2017.1810

25. Espinosa CD, Fry RS, Kocher ME, Stein HH. Effects of copper hydroxychloride and distillers dried grains with solubles on intestinal microbial concentration and apparent ileal and total tract digestibility of energy and nutrients by growing pigs. J Anim Sci. 2019;97(12):4904-4911. doi: 10.1093/jas/skz340.

26. Fondevila M, Herrer RM, Casallas MC, Abecia L, Ducha JJ. Silver nanoparticles as a potential antimicrobial additive for weaned pigs. Animal Feed Science and Technology. 2009;150(3-4):259269. doi: https://doi.org/10.1016/j.anifeedsci.2008.09.003

27. Gorlov IF, et al. Effect of feeding with organic microelement complex on blood composition and beef production of young cattle. Modern Applied Science. 2015;9(10):8-16. doi:10.5539/mas.v9n10p8

28. Henderson G, Cox F, Ganesh S, Jonker A, Young W, Global Rumen Census C, Janssen PH. Rumen microbial community composition varies with diet and host, but a core microbiome is found across a wide geographical range. Sci. Rep. 2015;5:14567. doi: 10.1038/srep14567

29. Huws SA, Creevey CJ, Oyama LB, Mizrahi I, Denman SE, Popova M, et al. Addressing global ruminant agricultural challenges through understanding the rumen microbiome: past, present, and future. Front Microbiol. 2018. 25(9):2161. doi: 10.3389/fmicb.2018.02161

30. Makaeva A, Atlanderova K, Miroshnikov S, Sizova E. Rumen microbiome of cattle after introduction of ultrafine particles in feed. FEBS Open Bio. 2019;9(S1):416.

31. Miroshnikova E, Arinzhanov A, Kilyakova Y, Sizova E, Miroshnikov S. Antagonist metal alloy nanoparticles of iron and cobalt: impact on trace element metabolism in carp and chicken. Human \& Veterinary Medicine. International Journal of the Bioflux Society. 2015;7(4):253-259.

32. Pietroiusti A, Magrini A, Campagnolo L. New frontiers in nanotoxicology: Gut microbiota/microbiome-mediated effects of engineered nanomaterials. Toxicol Appl Pharmacol. 2016;299:90-95. doi: https://doi.org/10.1016/j.taap.2015.12.017

33. Prasad R, Bhattacharyya A, Nguyen D. Quang nanotechnology in sustainable agriculture: recent developments, challenges, and perspectives. Front Microbiol. 2017;8:1014. doi: $10.3389 /$ fmicb.2017.01014 
34. Rosenberg E, DeLong EF, Lory S, Stackebrandt E, Thompson F, editors. The Prokaryotes: Prokaryotic Biology and Symbiotic Associations. 4th ed. Springer-Verlag Berlin Heidelberg; 2013: 607 p.

35. Torok VA, Percy NJ, Moate PJ, Ophel-Keller K. Influence of dietary docosahexaenoic acid supplementation on the overall rumen microbiota of dairy cows and linkages with production parameters. Can J Microbiol. 2014;60(5):267-275. doi: 10.1139/cjm-2013-0805

36. Veira DM. The role of ciliate protozoa in nutrition of the ruminant Journal of Animal Science. $1986 ; 63(5): 1547-1560$.

37. Walsh K. et al. Intake, digestibility and rumen characteristics in cattle offered whole-crop wheat or barley silages of contrasting grain to straw ratios. Anim Feed Sci Tech. 2009;148(2):192-213. doi: 10.1016/j.anifeedsci.2008.03.013

38. Wang MQ, Wang C, Li H, Du YJ, Tao WJ, Ye SS, He YD. Effects of chromium-loaded chitosan nanoparticles on growth, blood metabolites, immune traits and tissue chromium in finishing pigs. Biol Trace Elem Res. 2012;149(2):197-203. doi: 10.1007/s12011-012-9428-3

39. Wang MQ, Wang C, Li H, Du YJ, Tao WJ, Ye SS, He YD. Effects of chromium-loaded chitosan nanoparticles on growth, carcass characteristics, pork quality, and lipid metabolism in finishing pigs. Livest Sci. 2014;161:123-129. doi: 10.1016/j.livsci.2013.12.029

40. Wang C, Wang MQ, Ye SS, Tao WJ, Du YJ. Effects of copper-loaded chitosan nanoparticles on growth and immunity in broilers. Poult Sci. 2011;90(10): 2223-2228. doi: https://doi.org/10.3382/ps.2011-01511

41. Zeineldin M, Barakat R, Elolimy A, Salem AZM, Elghandour MMY, Monroy JC. Synergetic action between the rumen microbiota and bovine health. Microb Pathog. 2018;124:106-115. doi: https://doi.org/10.1016/j.micpath.2018.08.038

42. Zelenák I, Jalc D, Plachá I, Sviatko P, Vendrák T, Siroka P, Gyulai F. The effect of copper and cobalt supplementation on the digestibility of fibrous feed in sheep. Vet Med (Praha). 1992;37(4):221-229.

43. Zhu W, et al. Effects of dietary forage sources on rumen microbial protein synthesis and milk performance in early lactating dairy cows. J Dairy Sci. 2013;96(3):1727-1734. doi: $10.3168 /$ jds. $2012-5756$

Макаева Айна Маратовна, младший научный сотрудник центра «Нанотехнологии в сельском хозяйстве», Федеральный научный центр биологических систем и агротехнологий Российской академии наук, 460000, г. Оренбург, ул. 9 Января, 29, тел.: 8-919-842-46-99, е-mail: ayna.makaeva@mail.ru

Сизова Елена Анатольевна, доктор биологических наук, руководитель центра «Нанотехнологии в сельском хозяйстве», Федеральный научный центр биологических систем и агротехнологий Российской академии наук, 460000, г. Оренбург, ул. 9 Января, д. 29, тел.: 8-912-344-99-07, еmail: Sizova.L78@yandex.ru; профессор кафедры биологии и почвоведения, Оренбургский государственный университет, 460018, г. Оренбург, пр. Победы, 13

Атландерова Ксения Николаевна, младший научный сотрудник Испытательного центра ЦКП, Федеральный научный центр биологических систем и агротехнологий Российской академии наук, 460000, г. Оренбург, ул. 9 Января, 29, e-mail: atlander-kn@mail.ru

Поступила в редакцию 13 декабря 2019 г.; принята после решения редколлегии 16 декабря 2019 г.; опубликована 31 декабря 2019 г. / Received: 13 December 2019; Accepted: 16 December 2019; Published: 31 December 2019 